\title{
Introduction
}

\section{Korean Tradition in Modern Eastern Europe: Ideas, Myths and Realities}

\section{Chikako SHIGEMORI BUČAR*}

It is our great pleasure to introduce the first "Korean" issue of the Asian Studies journal. Since 1998, this journal has been published by the Department of Asian and African Studies of the Faculty of Arts, University of Ljubljana. In the last decade, much effort has been dedicated to Korea-related activities by this Department and, thanks to the fruitful cooperation with many important Korean academic and cultural institutions, the Department has successfully put in place some initial steps towards the establishment of a Chair of Korean studies. In this context, our special thanks go to Prof. Dr. Yoo Kwon Jong's contribution, which will be described more in detail below. Prof. Yoo Kwon Jong from Chung-ang University visited our Department for the first time already in January 2006 and was the first scholar to deliver a series of special lectures on Korean studies for our students. We are grateful for his constant encouragement and inspiration ever since.

The present issue of the journal, focusing on Korea, can be viewed as an important part of our endeavors in the development of Korean studies. Hence, we are very proud and honoured to be able to present several academic articles, which aim to uncover different aspects of Korean society and culture. However, the contributions published in this issue are not authored solely by the Korean scholars or scholars primarily specialized in Korean studies. Among others, one of the main goals of our Department is to establish a fruitful cooperation between East Asian scholars and present a coherent view of East Asian cultural commonalities. The rationale for proposing an East Asian perspective as a field of study is twofold. On the one hand, East Asian cultures embrace the cultural traditions of China, Japan, Korea, and Taiwan. On the other hand, the varied traditions in these cultures do not form a mechanical assemblage, but rather a comprehensive, developing, and systematic whole. Therefore, this issue also contains important contributions on Korean studies written by experts in Chinese and Japanese studies.

\footnotetext{
* Chikako SHIGEMORI BUČAR, PhD, Associate Professor, Department of Asian and African Studies, Faculty of Arts, University of Ljubljana, Slovenia. chikako.shigemori@guest.arnes.si
} 
The first section of the present volume is entitled Libraries, museums and national heritage. The first article in this section presents a thorough investigation of the library disputes in Korea which started as early as the 1950s. Against the specific historical background, Ryu Hyeonsook starts her examination by going through the terminological variation of "national", "central" and what may be translated as "national representative" libraries. It is very important to understand the specific situation in Korea where the National Library of Korea and the National Assembly Library coexist up to the present day. The article shows how political background may influence the cultural development of a nation, in this case, the order and structure of public services, which are closely related to people's everyday endeavours.

Jeff Kingston's contribution deals with politico-historical disputes between Korea and Japan which are deeply rooted in the colonial time of the two nations' history. His article takes us to the most current scenes of "history wars", such as the Rising Sun flag in manga exhibitions in the War Memorial of Korea in Seoul, statues of "comfort women" which are found not only in Seoul but also in several cities in the United States. The author clearly shows how symbols and heroic figures are often manipulated to become convenient tools for inflaming nationalistic and patriotic sentiments. The neighbouring "frenemies", according to Kingston, still have a long way to go before they can reach a convincing reconciliation.

The second section is entitled Korea and Japan: a precarious relationship and features articles focusing on relations between Korea and Japan, based upon their common cultural and historical background. Beatrix Mecsi of the ELTE University presents an interesting view on the myth of eternal life as a punishment, focusing on Pindola (or Binzuru) of Japan and the Lonely Saint in Korea. The central part of Mecsi's article concentrates on the lively description of the Korean deity associated to magic and immortality, often depicted with long white eyebrows. Already in the beginning of the $20^{\text {th }}$ century some scholars connected the Asian legendary figures with the wandering Jew from Jerusalem.

Nataša Visočnik presents sociological research on a recent phenomenon in an area in Kyoto, where marginalized groups of local citizens, among them generations of zainichi Koreans, struggle in a new form of community building. The machizukuri movement should be taken as a good model of self-governance and cooperation in today's urban life. Visočnik's fieldwork includes remnants of 
historical outcasts of Japanese society, the problem of buraku, as well as the most current measures taken for marginalized groups of different ages, nationalities and handicaps, and sees rather optimistic directions in the newly emerging multicultural and multifarious lifestyle of the $21^{\text {st }}$ century.

The next section carries the title of Korean philosophy: metaphysics and political theory. The range of contributions begins with Jana S. Rošker's article which turns a spotlight on Dasan (or Jeong Yak-yong), a Korean Confucian philosopher, and discusses his importance in understanding traditional East Asian streams of Confucian thought. Rošker's investigation into Dasan's background, life and work convincingly shows that this Korean Confucian philosopher can be viewed as one of the most prominent landmarks in the history of East Asian Confucianisms.

Yoo Kwon Jong's special contribution in Korean deals with the political history of Jeong Do-jeon who was the most substantial contributor to the making of the Joseon dynasty. Without Jeong Do-jeon's planning and practice, the Joseon dynasty could not have been established and moreover, the dynasty would not have existed for almost 500 years.

Another contribution related to Korean Confucianism is by Martina Greif and Jana S. Rošker, investigating a Taiwanese perspective on Confucianism, taking up the work by Prof. Lee Ming-huei. The authors of this article assert that the development of Confucian studies must be viewed in a broader cultural context, taking into account all regions of Eastern Asia, including Korea.

Overall, the present issue covers old and new, traditional and contemporary issues, related to Korea. What is common to all contributions is that we cannot neglect and should not fail to keep in mind the broader perspective of East Asia as a whole. In this sense, the present issue on Korean studies can be seen as one of the first steps leading towards the development of "East Asian cultures" as a valid new field of study with a rich and distinct "unity in diversity". It is our firm belief that an East Asian perspective opens up a novel vista for future investigations, pointing to new aspects and questions, and opening new horizons for the appreciation of the diversity and variety of East Asian cultures.

I wish all readers an enjoyable reading.

Chikako Shigemori Bučar, Guest Editor 